\title{
Monocular optokinetic nystagmus in humans with age-related maculopathy
}

\author{
Richard V Abadi, Mary Pantazidou
}

\begin{abstract}
Aim-To investigate full field monocular optokinetic nystagmus $(\mathrm{OKN})$ in patients with age-related maculopathy (ARM) and relative central scotoma.

Methods-Six patients aged 59-88 years with bilateral ARM and an aged-matched control group of six patients aged 54-83 years were examined. Visual fields were assessed with a Humphrey field analyser using the threshold 30-1 routine. Monocular full field horizontal optokinetic stimuli were presented on a hemicylindrical screen subtending $172^{\circ}$ horizontally and $50^{\circ}$ vertically. The stimulus was a projected random dot pattern and three stimulus velocities were used, 30,50 , and $70 \%$ in both nasalward and temporalward directions. Each trial lasted between 30 and 40 seconds and eye movements were monitored using infrared oculography.

Results-The ARM patients had relative central scotomas with an average depth of 10 dB. Neither the ARM nor the agematched groups displayed any directional preponderance or a buildup of the slow phase eye velocity with time. No statistically significant difference in the gain was found between the two groups $(p>0.05)$.

Conclusions-Marked central field loss in ARM does not significantly impair OKN gain. This supports the view that complete central retinal integrity is by no means essential and that the peripheral retina provides an important input to the generation of $\mathrm{OKN}$.
\end{abstract}

(Br F Ophthalmol 1997;81:123-129)

Optokinetic nystagmus (OKN) is a rhythmic involuntary conjugate oscillation of the eyes in response to a large moving visual scene..$^{1-3}$ The nystagmus is made up of slow phases in the direction of stimulus movement which are interrupted at regular intervals by fast phases (saccades) in the opposite direction. A measure of the effectiveness of the optokinetic response in reducing retinal image slip is the gain which is defined as the ratio of the slow phase eye velocity to the stimulus velocity.

Over the past 20 years a number of researchers have examined the effect of stimulus size and position on the gain of OKN. ${ }^{4-10}$ When selective stimulation of the central retina has been compared with peripheral retinal stimulation (by masking off portions of the central regions of the visual field), the OKN gains have been found to be reduced. Typically the OKN gain for a full field stimulus moving at a velocity of $40 \%$ is reduced by a factor of 2 when the central $12.5^{\circ}$ of the field is masked off. ${ }^{11}$ These studies illustrate that, although the gain of the $\mathrm{OKN}$ is significantly higher for combined central and peripheral retinal image slip at low stimulus velocities, the peripheral retina is still capable of giving a reasonable response.

The effect of central visual field loss from pathological central scotomas has also been investigated. In 1982 Yee and his colleagues ${ }^{12}$ published a very brief report that six elderly patients, with age-related maculopathy (ARM) and unilateral central scotomas exhibited a slight lowering of the horizontal $\mathrm{OKN}$ gain to a unidirectional motion of vertical stripes. The size of the scotomas ranged from $5^{\circ}$ to $15^{\circ}$ but no indication as to their depth was given.

The purpose of this study was, therefore, to extend the work of Yee and his colleagues. With the inclusion of a control group we have examined in greater detail whether the presence of a relative central scotoma influences the gain of monocular OKN and, further, whether there is any disturbance in the symmetry of the OKN response in patients with ARM.

\section{Patients and methods}

SUBJECTS

Six patients (age range 59-88 years; mean 72.3 (SD 10.1)) with bilateral ARM participated in the experiments. Ophthalmic investigations revealed that each patient exhibited a dry type of ARM. ${ }^{13-15}$ Monocular visual acuities, with a
Department of Optometry and Vision Sciences, UMIST, Manchester R V Abadi

M Pantazidou

Correspondence to: Richard V Abadi, Department of Optometry and Vision Sciences, UMIST, PO Box 88, Manchester M60 1QD.
Table 1 Clinical details of the subjects with age-related maculopathy

\begin{tabular}{|c|c|c|c|c|c|c|}
\hline \multirow[b]{2}{*}{ Subject } & \multirow[b]{2}{*}{ Age (years) } & \multirow[b]{2}{*}{ Sex } & \multicolumn{2}{|c|}{ Visual acuity (logMAR) } & \multicolumn{2}{|c|}{ Visual field defect (size and average depth) } \\
\hline & & & $R E$ & $L E$ & $R E$ & $L E$ \\
\hline 1 & 88 & $M$ & 0.85 & 0.95 & $\pm 6^{\circ} ; 10 \mathrm{~dB}$ & $\pm 12^{\circ} ; 13 \mathrm{~dB}$ \\
\hline 2 & 79 & $\mathrm{~F}$ & 1.17 & 1.01 & $\pm 8^{\circ} ;-$ & $\pm 8^{\circ}$ \\
\hline 3 & 70 & $\mathrm{M}$ & 0.45 & 0.47 & $\pm 6^{\circ} ; 3 \mathrm{~dB}$ & $\pm 6^{\circ} ; 6 \mathrm{~dB}$ \\
\hline 4 & 59 & $M$ & 0.07 & 0.61 & $\pm 1^{\circ} ; 8 \mathrm{~dB}$ & $\pm 6^{\circ} ; 9 \mathrm{~dB}$ \\
\hline 5 & 72 & $\mathrm{~F}$ & 0.60 & HM & $\pm 12^{\circ} ; 16 \mathrm{~dB}$ & - \\
\hline 6 & 66 & M & 0.86 & 1.17 & $\pm 12^{\circ} ; 20 \mathrm{~dB}$ & $\begin{array}{l}8^{\circ} \mathrm{SN}: \mathrm{IN} ; 22 \mathrm{~dB} \\
6^{\circ} \mathrm{ST} ; 3 \mathrm{~dB}\end{array}$ \\
\hline
\end{tabular}

$\mathrm{dB}=$ decibels. $\mathrm{HM}=$ hand movements. $\mathrm{IN}=$ inferior nasal. $\mathrm{SN}=$ superior nasal. $\mathrm{ST}=$ superior temporal. 

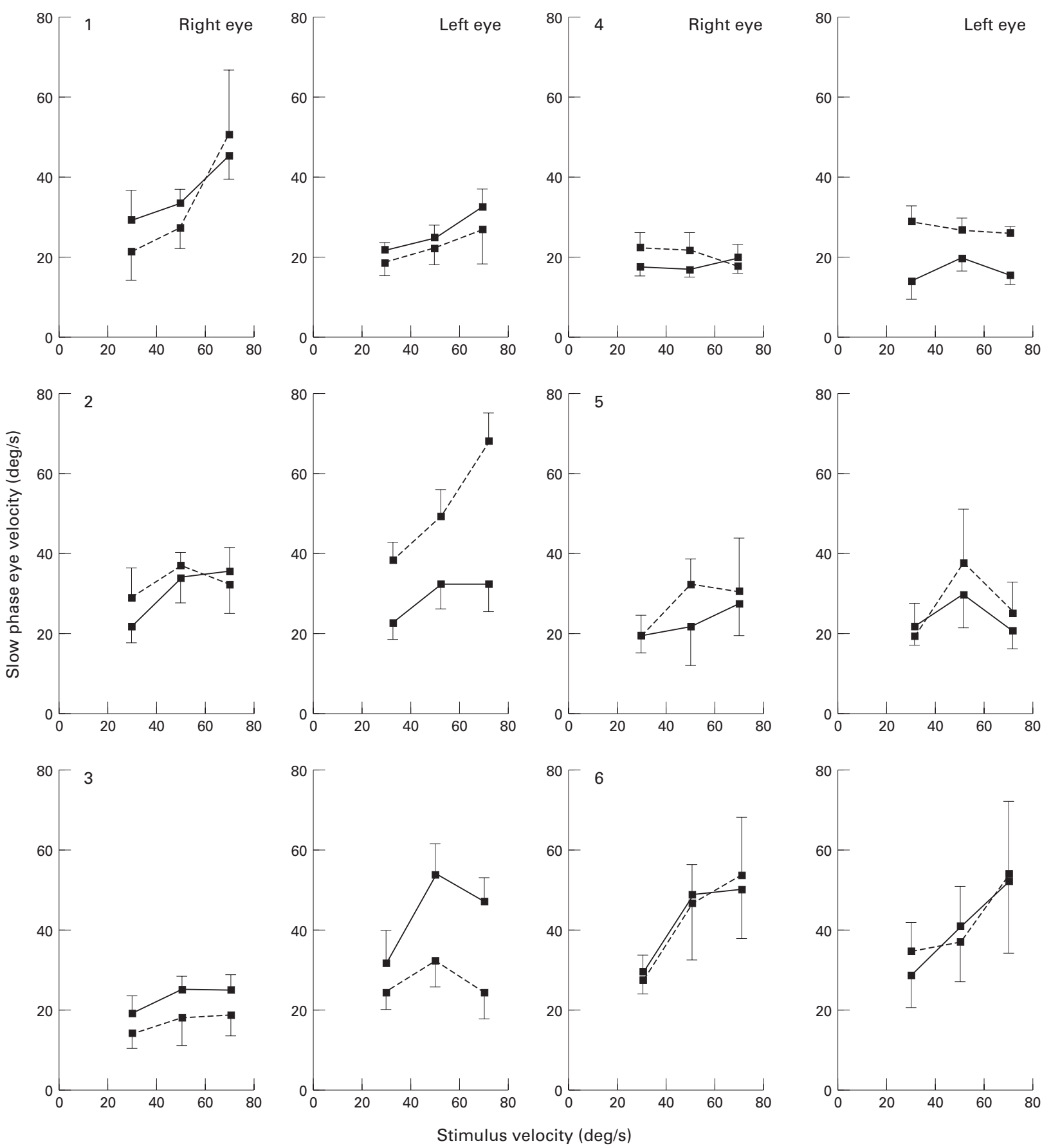

Figure 1 The relation between slow phase velocity and stimulus velocity for the right and left eye of each of six age-matched control patients for unidirectional optokinetic stimulation. Three stimulus velocities are illustrated: 30,50 , and $70^{\circ} / \mathrm{s}$. The direction of the stimulus was either nasal-temporal (solid line) or temporal-nasal (broken line). The vertical bars indicate the standard deviation of the mean of 10 slow phases.

$96 \%$ contrast Regan chart, ranged from 1.17 to $0.07 \log M A R$, with one eye only perceiving hand movements. The aged-matched control group consisted of six patients (age range 54-83 years; mean 70.3 (SD 9.7)). They had no history of ocular disease, showed no signs of ocular pathology, and monocular visual acuities ranged from 0.21 to $-0.19 \log M A R$. None of the patients in any of the three groups had a history or sign of strabismus.

VISUAL FIELDS

Monocular central visual fields were assessed with a Humphrey field analyser (model 630) using the threshold 30-1 routine. ${ }^{1617}$ Each session commenced with a 5 minute adaptation period during which the patients were given instructions on the perimetric task. Incremental target intensities were presented in 72 positions over $30^{\circ}$ of the central field using a target size of $0.25 \mathrm{~mm}^{2}$ and a background luminance of 45 lux. For foveal threshold assessment, the fixation point was replaced by a diamond pattern of four yellow light spots and the test target was presented at the centre of the visual field. The duration of the test stimulus was set at $200 \mathrm{~ms}$ and presented in random order. Natural pupils and the appropriate refractive 

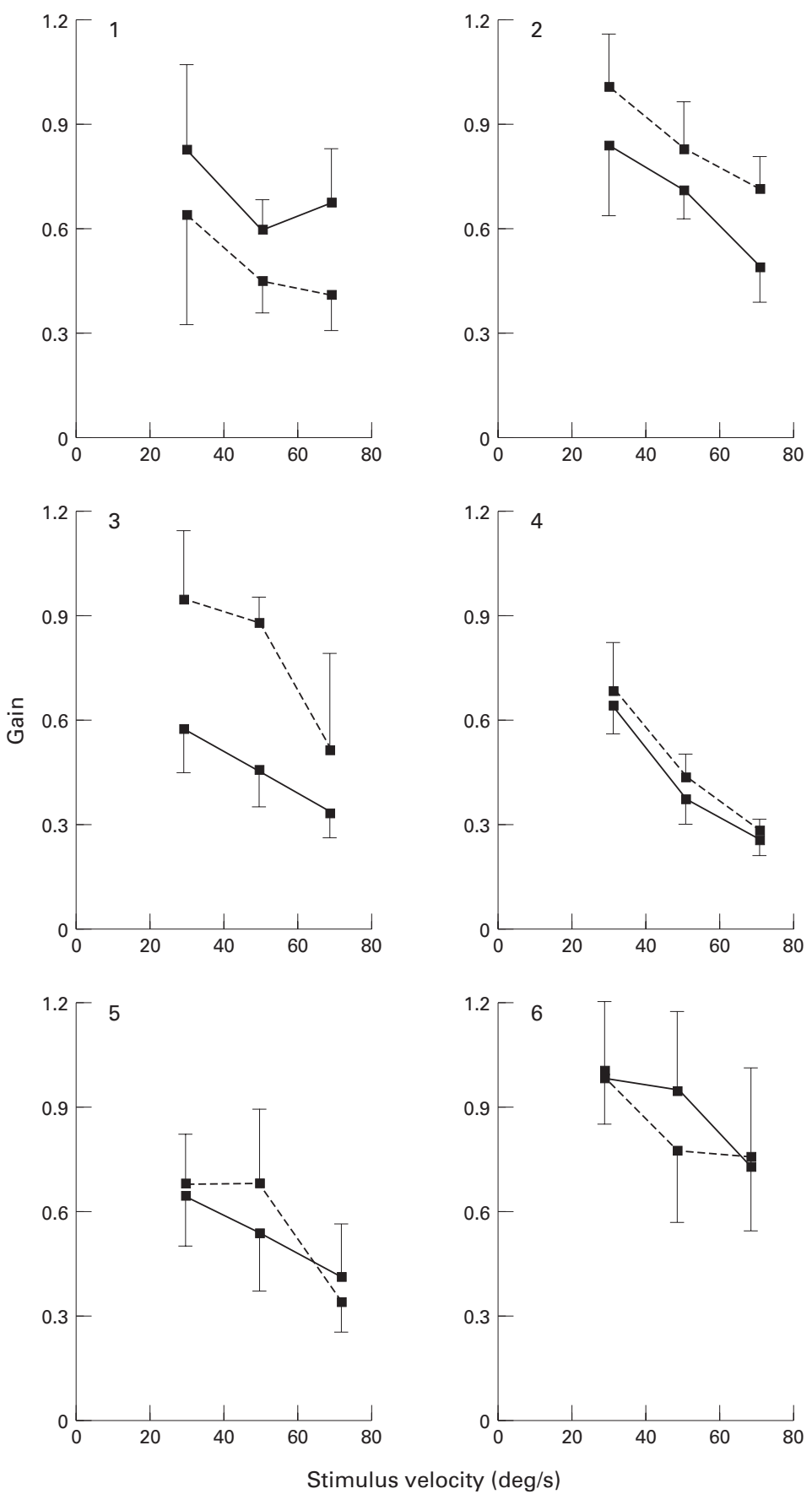

Figure 2 The relation between optokinetic gain and stimulus velocity for each of the six age-matched control patients. The direction of the stimulus was either nasal-temporal or temporal-nasal and the data of the optokinetic responses, elicited under both conditions, have been averaged for each patient's right (solid line) and left eye (broken line). Vertical bars represent the standard deviation of the mean of 20 slow phases (10 measurements for each of the two directions).

correction for the $33 \mathrm{~cm}$ viewing distance were used. Amsler charts were also used to indicate areas of field distortion and/or field loss.

OPTOKINETIC STIMULI

Full field horizontal optokinetic stimuli were presented on a hemicylindrical white screen subtending $172^{\circ}$ horizontally and $50^{\circ}$ vertically at a distance of 1.3 metres from the subject. The stimulus consisted of a projected random dot pattern (contrast $85 \%$ ), each dot subtending a diameter between $1.5^{\circ}$ and $2.5^{\circ}$, giving a dot density on the screen of 46 dots $/ \mathrm{m}^{2}$. Three stimulus velocities were used, 30, 50, and $70 \%$, in both rightward and leftward directions and the duration of each trial run was between 30 and 40 seconds.

EYE MOVEMENT RECORDING

Monocular horizontal eye movements were recorded for both eyes separately using infrared oculography (resolution $10^{1}$ arc) and displayed on a four channel strip chart recorder. Head movements were minimised with a chin cup and forehead rest and the screen was viewed monocularly. All subjects were instructed to gaze passively at the centre of the screen and to keep the stimulus as clear as possible. A calibration procedure of plus or minus $8^{\circ}$ horizontal saccades to a $0.5^{\circ}$ circular white target projected by a mirror galvanometer was undertaken at the start of the experimental run and repeated before each change in either stimulus velocity or direction. The stimulus was made to move either temporalwards (nasal to temporal, N-T) or nasalwards (temporal to nasal, T-N). At least $5 \mathrm{sec}-$ onds after stimulus onset the mean velocity of 10 consecutive slow phases was calculated for each stimulus velocity and stimulus direction. OKN slow phase velocity was determined from the gradient drawn through each slow phase.

The tenets of the Declaration of Helsinki were followed in this research. Informed consent was obtained from all subjects after the nature and the possible consequences of the study had been explained.

\section{Results}

VISUAL FIELDS

The age-matched control group exhibited no distortions for the Amsler grid assessment and incremental threshold testing showed no loss of sensitivity within $30^{\circ}$ of the centre of the visual field. All the patients with ARM indicated the presence of distortion and missing areas of the Amsler grid. With the Humphrey field analyser all exhibited foveal and parafoveal relative scotoma with the field defect size varying from $1^{\circ}$ to $12^{\circ}$ from the centre. Generally the scotomas were regular with the average depth of defect being around $10 \mathrm{~dB}$ (see Table 1). It was not possible to carry out a quantitative visual field evaluation on patient No 5 but an Amsler chart assessment revealed a field loss of plus or minus $8^{\circ}$.

\section{OPTOKINETIC RESPONSE}

All the eye movement traces showed a characteristic OKN with no slow phase velocity buildup. The relation between slow eye velocity and stimulus velocity during monocular N-T and T-N target motion for each of the six agematched control patients are shown in Figure 1. Generally asymmetries for the two stimulus motion directions were small. In order to give a clearer indication of the efficiency of the OKN, the gain was plotted against stimulus velocity for the right (solid lines) and left (broken lines) eyes (Fig 2). Typically gains were found to be between 0.9 and 0.6 for stimulus velocities of $30 \%$ but would drop by around 0.3 for 

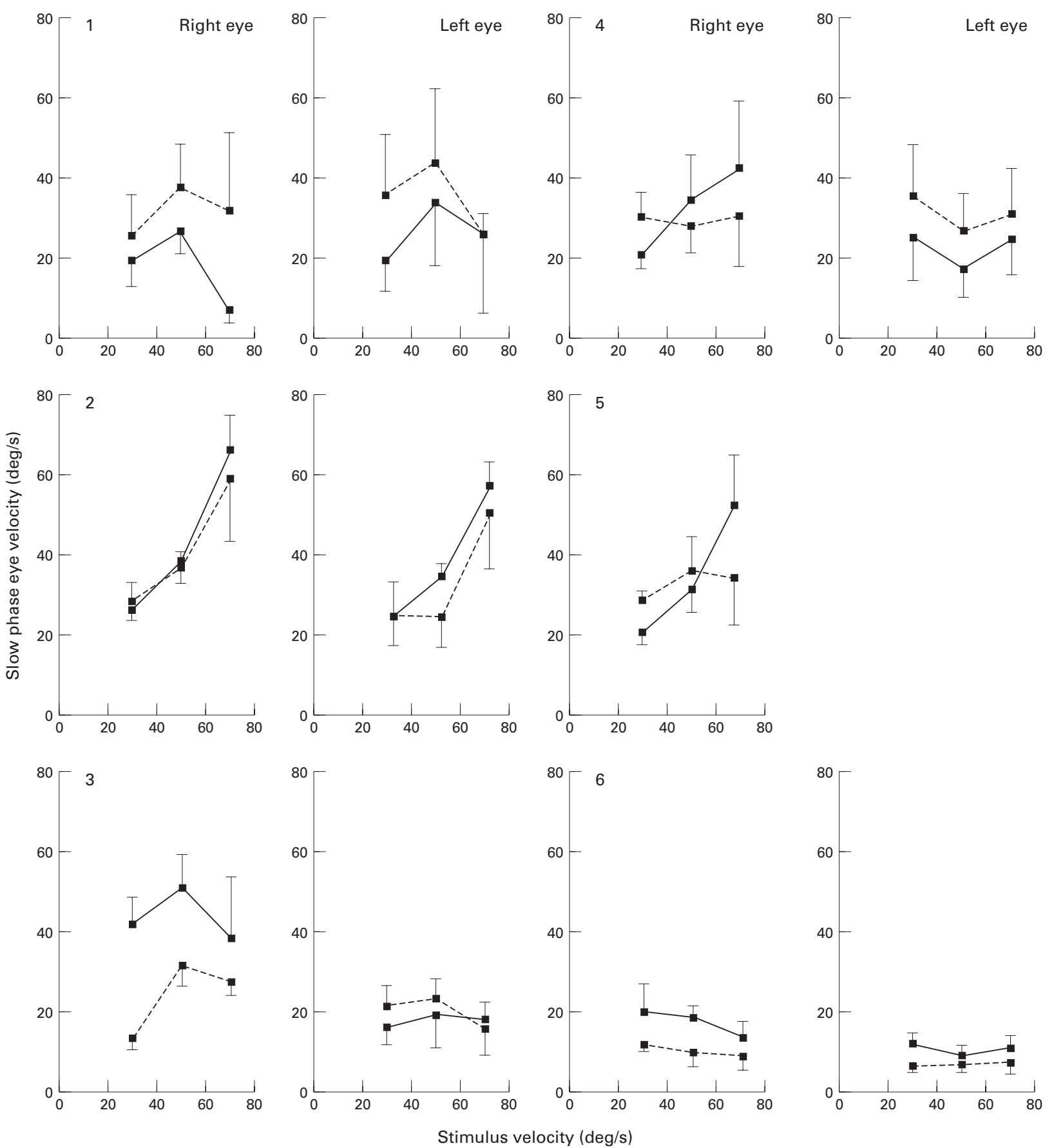

Figure 3 The relation between slow phase velocity and stimulus velocity for the right and left eye of each patient with ARM under unidirectional optokinetic stimulation. Three stimulus velocities are illustrated: 30, 50, and $70^{\circ} / \mathrm{s}$. The direction of the stimulus was either nasal-temporal (solid line) or temporal-nasal (broken line). The vertical bars indicate the standard deviation of the mean of 10 slow phases. The left eye of patient No 5 was not examined.

velocities of $70 \%$ s. The mean gains for the right and left eyes were found to be 0.75 (SD 0.15) and $0.82(0.17)$ respectively and are a little lower than can be expected in a much younger control group. ${ }^{1011}$ No statistically significant directional asymmetries were apparent at any of the three stimulus velocities ( $p>0.05$, Student's paired $t$ test).

Slow phase eye velocity and OKN gain plots for each of the six patients with ARM are illustrated in Figures 3 and 4, respectively. Gains were typically between 0.9 and 0.6 . No statistically significant monocular directional asym- metry in the mean slow phase eye velocity was found for any of the patients with ARM ( $p$ $>0.05$ ) at any of the three stimulus velocities (Fig 5). Finally, Figure 6 shows how the mean OKN gain is affected by the stimulus velocity for the two patient groups. There was no statistically significant difference between the two functions $(p>0.05)$.

\section{Discussion}

MONOCULAR OKN GAIN

The aim of this study was to investigate the effect of relative central scotomas caused by 

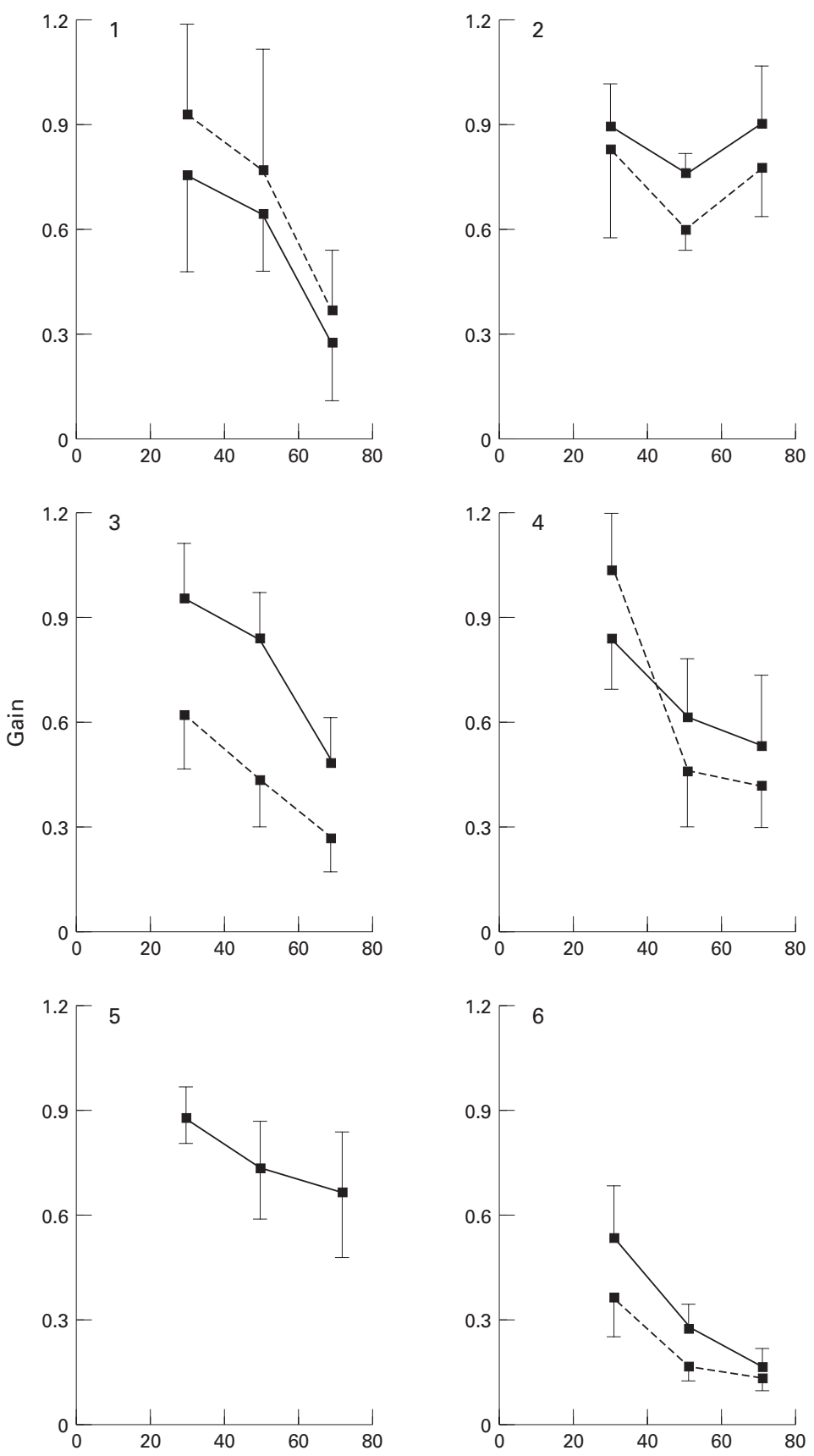

Stimulus velocity $(\mathrm{deg} / \mathrm{s}$ )

Figure 4 The relation between optokinetic gain and stimulus velocity for each of the six patients with ARM. The direction of the stimulus was either nasal-temporal or temporal-nasal and the data of the optokinetic responses, elicited under both conditions, have been averaged for each patient's right (solid line) and left eye (broken line). Vertical bars represent the standard deviation of the mean of 20 slow phases (10 measurements for each of the two directions) The left eye of patient No 5 was not examined.

ARM on the monocular horizontal optokinetic response. To examine the possibility of whether the age of the patient may influence the $\mathrm{OKN}$ gain an aged-matched control group was also investigated. The OKN gain of the agematched group was found to be consistent with the findings reported in the literature. ${ }^{19-22}$ This decrease in OKN performance is not only restricted to patients above 60 years of age but reflects the continuous decline in $\mathrm{OKN}$ gain which affects younger patients from the age of 40 onwards. It has also been reported that both

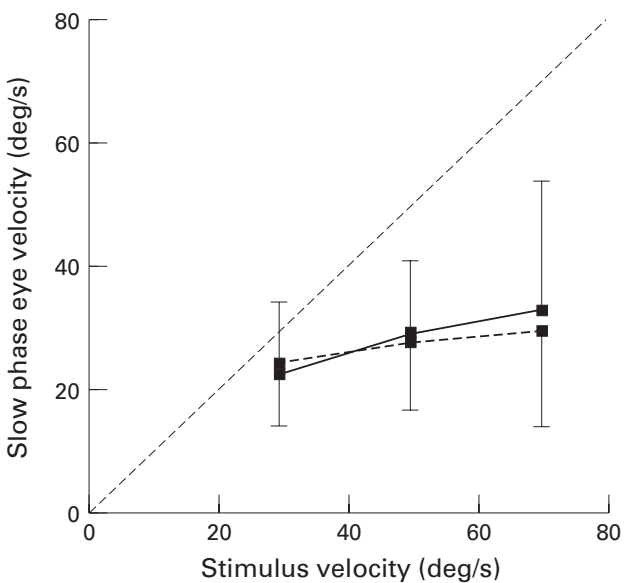

Figure 5 The relation between the mean slow phase eye velocity and stimulus velocity of the six patients with ARM, for nasal-temporal (solid line) and temporal-nasal (broken line) directions. Vertical bars indicate the standard

deviation of the mean which is made up of the 11 ARM eyes tested. The line at $45^{\circ}$ to the two coordinates represents a gain of unity.

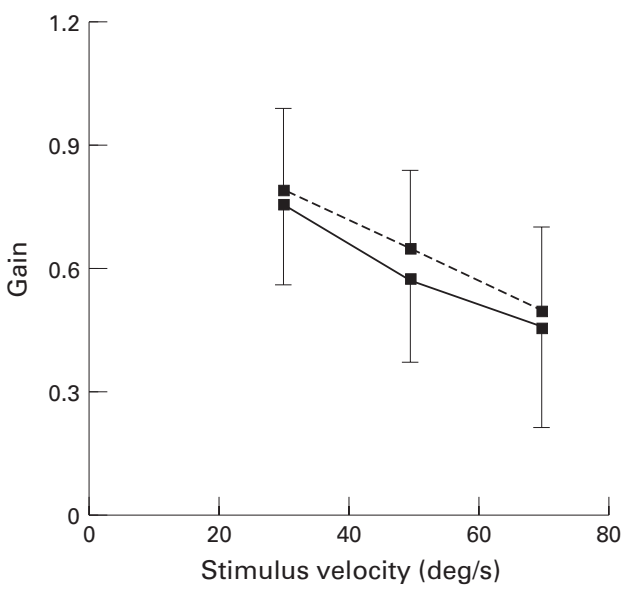

Figure 6 The effect of full field unidirectional stimulus motion on the averaged gain for the age-matched control (broken line) and age-related maculopathy (ARM) (solid line) patient groups. Vertical bars indicate the standard deviation of the mean for the control and ARM groups.

the early and late components of the OKN are affected suggesting that both the direct smooth pursuit element, and the indirect velocity storage mechanism have corresponding reductions in efficiency. ${ }^{19}$ Not surprisingly, functional agerelated changes in the gain of the visual tracking system have also been reported. ${ }^{23}$

Although Figure 6 illustrates that the mean gains for the control and ARM patient groups did not differ significantly there were, on occasions, large intrasubject OKN differences. ${ }^{245}$ This variability is not unexpected in $\mathrm{OKN}$ studies since, although the experimental task is a passive one, the level of attention given to the stimulus during each experimental run can strongly influence the gain of the $\mathrm{OKN} .{ }^{26-28} \mathrm{It}$ is pertinent to note that some investigators using artificial central field scotomas found large reductions in OKN gain. ${ }^{467}{ }^{29}$ However, it is likely that the nature of their experimental design may have been, in part, responsible for this discrepancy. In particular, the edges of the masks used to create the central field loss are 
very likely to have contributed to the suppression of the OKN. ${ }^{81125}$

Our present findings confirm those obtained by Yee and his colleagues ${ }^{12}$ who also reported a modest but not significant lowering of OKN gain in ARM. Thus it appears that in patients with ARM a marked reduction of macular vision per se does not dramatically impair OKN gain nor reveal any increased preference for temporal to nasal stimuli. It thus appears that the remaining central retinal function together with the intact peripheral retina must provide an important drive to the optokinetic response. Support for this argument comes from an OKN study on patients with retinal lesions by Baloh and colleagues ${ }^{30}$ which suggested that an overlap in signals derived from the fovea and peripheral retina may occur, since central and peripheral retinal lesions are not entirely selective in their effect on either the direct or indirect OKN pathway.

MONOCULAR OKN ASYMMETRY

There are now a number of reports that in the first few weeks after birth infants show a strong monocular OKN asymmetry with the T-N response being readily elicited while the $\mathrm{N}-\mathrm{T}$ response is weak or absent. Thereafter, symmetrical responses are recorded at around 3 months. ${ }^{31-33}$ These developmental changes in monocular OKN have been linked to cortical binocular development. ${ }^{34-36}$ One possible suggestion for this is that the postnatal development of binocularly driven cortical projections to the nucleus of the optic tract supplement the innate direct inputs and thereby provide the N-T response. ${ }^{3738}$ An alternative proposal for the initially poor response to temporalward moving stimuli is that in newborn infants the visual cortex has a directional asymmetry to motion processing of nasalward and temporalward stimulus motion. ${ }^{39-41}$

In 1986, Van Die and Collewijn ${ }^{9}$ reported larger monocular OKN gains for T-N compared with N-T field motion in three patients with central field scotoma secondary to retinal or neural disease. Long term loss of foveal function in patients with achromatopsia has also been reported to be responsible for a preferred T-N directional OKN sensitivity. ${ }^{42} 43$ Similarly, monocular OKN asymmetries have been described in patients with long standing strabismic amblyopia. ${ }^{44-46}$ It is clear, therefore, that directional disturbances of $\mathrm{OKN}$ are determined in part by the onset time of the foveal pathology as well as the position and depth of the scotoma in the visual field. This is compatible with the view that the development of a symmetrical monocular OKN requires an intact and functionally normal fovea during early infancy. ${ }^{32478}$ Moreover, the presence of a nystagmus often seen in patients with a congenital foveal pathology will undoubtedly modify the optokinetic response and can make OKN gain evaluations difficult. ${ }^{49-52}$

OKN AND CENTRAL SCOTOMAS

In conclusion, there is now much evidence to suggest that although the central retina strongly influences the human $\mathrm{OKN}$, gains can reach near normal levels with peripheral retinal stimulation. ${ }^{1011}$ It remains to be established whether the intact peripheral retina alone is capable of giving an appropriate feedback signal for the optokinetic response or whether residual inputs from the central retina such as a cortical filling in mechanism compensates for the absence of central vision. In support of the latter view, patients with a scotoma in their visual field often report that contours from the rest of the visual field fill in to occupy the scotoma. ${ }^{53}$ Recently, Ramachandran and Gregory ${ }^{54}$ concluded that spatial filling in is an active neural process that probably involves creating an actual neural representation of the surround rather than merely ignoring the absence of information from the scotoma. This situation could well occur in ARM, where a spatial temporal perceptual completion may have filled in the missing contours of the dot pattern of the optokinetic stimulus which fell within the area of the relative scotoma. Whatever the physiological mechanism, the conclusion drawn from this study provides evidence that complete central retinal integrity is by no means essential for the generation of high OKN gains. Thus the visual system of patients with functional macular loss acquired late in life is still capable of providing reasonable visually driven image stabilisation during whole field motion.

1 Collewijn $\mathrm{H}$. The oculomotor system of the rabbit and its plasticity. In: Studies of brain function. Vol 5. New York: plasticity. In: Springer, 1981 .

2 Carpenter RHS. Movements of the eyes. London: Pion, 1988. HO, eds. The vestibulo-ocular reflex and vertigo. New York: Raven Press, 1993:163-83.

4 Cheng M, Outerbridge JS. Optokinetic nystagmus during selective retinal stimulation. Exp Brain Res 1975;23:12939 .

5 Dichgans J. Optokinetic nystagmus as dependent on retinal periphery via the vestibular nucleus. In: Baker R, Berthoz A, eds. Control of gaze in brainstem neurones. Vol 1. Developments in neurosciences. Amsterdam: Elsevier, 1977:261-7.

6 Dubois MFW, Collewijn H. Optokinetic reactions in man elicited by localised retinal motion stimuli. Vision Res 1979; 19:1105-15.

7 Van Die GC, Collewijn H. Optokinetic nystagmus in man. Role of central and peripheral retina and occurrence of Role of central and peripheral retina and

8 Howard IP, Ohmi $M$. The efficiency of the central and peripheral retina in driving human optokinetic nystagmus. Vision Res 1984;24:969-76.

9 Van Die GC, Collewijn H. Control of human optokinetic nystagmus by the central and peripheral retina: effects of partial visual field masking, scotopic vision and central retinal scotomata. Brain Res 1986;383:185-94.

10 Abadi RV, Pascal E. The effects of simultaneous central and peripheral field motion on the optokinetic response. Vision Res 1991;31:2219-25.

11 Abadi RV, Howard IP, Ohmi M. The rise time and steady-state gain of the human optokinetic response (OKR). Invest Ophthalmol Vis Sci 1994;35:2035.

12 Yee RD, Baloh RW, Honrubia V, Jenkins HA. Pathophysiology of optokinetic nystagmus. In: Honrubia V, Brazier MA, ogy of optokinetic nystagmus. In: Honrubia V, Brazier MA, 251-75.

13 Sarks SH. Ageing and degeneration in the macular region: a clinico-pathological study. Br f Ophthalmol 1976;60:32441

14 Young RW. Pathophysiology of age-related macular degeneration. Surv Ophthalmol 1987;31:291-306.

15 Bressler NM, Bressler SB, Fine SL. Age-related macular degeneration. Surv Ophthalmol 1988;32:375-413.

16 Swann PG, Lovie-Kitchin JE. Age-related maculopathy. I A review of its morphology and effects on visual function. Ophthal Physiol Opt 1990;10:149-58.

17 Haley MJ. The field analyser primer-Allergan Humphrey. San Leandro, California, 1986.

18 Anderson RD. Testing the field of vision. Chicago: CV Mosby, 1992.

19 Simons B, Buttner U. The influence of age on optokinetic nystagmus. Eur Arch Psychiatr Neurol Sci 1985;234:369-73. 
20 Chiba Y, Furuya N. Aging and reference values of the parameters in optokinetic nystagmus. Nippon Fibiinkoke Gakkai Kaiho 1989;92:1416-23.

21 Ura M, Pfaltz CR, Allum JH. The effect of age on the visuoand vestibulo-ocular reflexes of elderly patients with vertigo. Acta Otolaryngol Suppl (Stockh) 1991;481:399402.

22 Baloh RW, Jacobson KM, Socotch TM. The effect of aging on visual-vestibulo-ocular responses. Exp Brain Res 1993; 95:509-16.

23 Zackon DH, Sharpe JA. Smooth pursuit in senescence: effects of target acceleration and velocity. Acta Otolaryngol 1987;104:290-7.

24 Dubois MRW, Collewijn H. Optokinetic reactions in man elicited by localised retinal motion stimuli. Vision Res 1979; 19:1105-15.

25 Abadi RV, Howard IP, Ohmi M. The effect of central and peripheral stimulation on the rise-time and steady-state
gain of human optokinetic nystagmus. Perception (submitted).

26 Dichgans J, Nauck B, Wolpert E. The influence of attention, vigilance and stimulus area on optokinetic and vestibular nystagmus and voluntary saccades. In: Zikmund V, ed. The oculomotor system and brain functions. London: Butterworths, 1973:279-94.

27 Magnusson M, Pyykko I, Jantti V. The effect of alertness and attention on optokinetic nystagmus in man. $A m \mathcal{F}$ Otolaryngol 1985;6:419-25.

28 Pola J, Wyatt HJ. The role of attention and cognitive processes. In: Miles FA, Wallman J, eds. Visual motion and its role in the stabilization of gaze. Amsterdam: Elsevier, 1993:371-92.

29 Gresty M, Halmagyi M. Following eye movements in the absence of central vision. Acta Otolaryngol 1979;87:47783.

30 Baloh RW, Yee RD, Honrubia V. Clinical abnormalities of optokinetic nystagmus. In: Lennerstrand G, Zee DS, Keller EL, eds. Functional basis of ocular motility disorders. Wenner Gren Symposium Series 37. Oxford: Pergamon Press, 1982: Gren Sympc $311-20$.

31 Atkinson J, Braddick O. Development of optokinetic nystagmus in infants: an indicator of cortical binocularity? In:
Fisher DF, Monty RA, Senders JW, eds. Eye movements: cognition and visual perception. Hillsdale, NJ: Erlbaum, 1981:53-64.

32 Naegele JR, Held R. The post-natal development of monocular optokinetic nystagmus in infants. Vision Res 1982;22:341-6.

33 Mohn G. The development of binocular and monocular optokinetic nystagmus in human infants. Invest Ophthalmol Vis Sci 1989;40 (suppl): 49.

34 Braddick O. Orientation and motion-selective mechanisms in infants. In: Symons K, ed. Early visual development: nor mal and abnormal. New York: Oxford University Press, 1993.

35 Tychsen L. Motion sensitivity and the origins of infantile strabismus. In :Symons K ,ed. Early visual development: nor-
mal and abnormal. New York: Oxford University Press, 1993:364-90.
36 Harris LR, Lewis TL, Maurer D. Brainstem and cortical contributions to the generation of horizontal eye movecontributions to the generation of horizontal
ments in humans. Vis Neurosi $1993 ; 10: 247-59$.

37 Schor CM, Narayan V, Westall C. Postnatal development of optokinetic after nystagmus in human infants. Vision Res 1983;3:1643-7.

38 Hoffmann KP. The influence of visual experience on the ontogeny of the optokinetic reflex in mammals. In: Keller FL, Zee DS, eds. Adaptive processes in visual and oculomotor systems. Oxford: Pergamon, 1986.

39 Norcia AN, Garcia H, Humphry R, Holmes A, Orel-Bixler D. Anomalous motion VEP's in infants and in infantile esotropia. Invest Ophthalmol Vis Sci 1991;32:436-9.

40 Wattam-Bell J. The development of maximum displacement limits for discrimination of motion direction in infancy. Vision Res 1992;32:621-30.

41 Wattam-Bell JRB. Development of visual motion processing. In: Vital-Durand F, Atkinson J, Braddick O, eds. Infant vision. Oxford: Oxford University Press, 1996:79-94.

42 Baloh RW, Yee RD, Honrubia V. Optokinetic asymmetry in patients with maldeveloped foveas. Brain Res 1980;186: 211-6.

43 Yee RD, Baloh RW, Honrubia V. Eye movement abnormalities in rod monochromacy. Ophthalmol 1981;88:1010-8.

44 Schor CM, Levi DM. Disturbance of small field horizontal and vertical optokinetic nystagmus in amblyopia. Invest Ophthalmol Vis Sci 1980;19:668-83.

45 Westall CA, Schor CM. Asymmetries of optokinetic nystagmus in amblyopia: the effect of selected retinal stimulation. Vision Res 1985;25:1431-8.

46 van Hof-van Duin J, Mohn G. Monocular and binocular optokinetic nystagmus in humans with defective stereopsis. Invest Ophthalmol Vis Sci 1986;27:574-83.

47 Roy MS, Lachapelle P, Lepore F. Maturation of the optokinetic nystagmus as a function of the speed of stimulation in fullterm and preterm infants. Clin Vis Sci 1989;4:357-66.

48 Lewis TL, Maurer D, Smith RJ, Haslip JK. The development of symmetrical optokinetic nystagmus during infancy. Clin Vis Sci 1992;7:211-8.

49 Halmagyi GM, Gresty MA, Leech J. Reversed optokinetic nystagmus and clinical significance. Ann Neurol 1980;7: 429-35.

50 Abadi RV, Dickinson CM, Lomas MS. Inverted and asymmetrical optokinetic nystagmus. In: Lennerstrand G, Zee DS, Keller EL eds. Functional basis of ocular motility disorders. Wenner-Gren Symposium Series 37. Oxford: Pergamon Press, 1982:143-6.

51 Abadi RV, Dickinson CM. The influence of preexisting oscillations on the binocular optokinetic response. Ann Neurol 1985;17:578-86.

52 Dickinson CM, Abadi RV. Pursuit and optokinetic responses in latent/manifest latent nystagmus. Invest Ophthalmol Vis Sci 1990;31:1599-614.

53 Sergent J. An investigation into perceptual completion in blind areas of the visual field. Brain 1988;111:347-73.

54 Ramachandran VS, Gregory RL. Perceptual filling in of artificially induced scotomas in human vision. Nature 1991;350:699-702. 